\title{
Repositioning SOZECOM, Nigeria for Navigating the Digital Economy
}

\author{
Muhammad Lawal Maidoki \\ Sokoto State Zakat and Waqf (Endowment) Commission
}

\begin{abstract}
Sokoto State Zakat and Waqf (Endowment) Commission aims to eradicate extreme poverty among the poor, vulnerable and mostly rural people inhabiting Sokoto state in North-western Nigeria. To achieve this aim, SOZECOM is currently restructuring its zakat, waqf and general administration processes. Part of the restructuring is the need to utilize the extensive network of paid and volunteer personnel, vast amount of data and several collaborative efforts with other institutions inorder to explore the potentials of digital finance in the administration of zakat and waqf. A major constraint toward the realization of this aim is limited digital capability. As a first imperative the need to develop SOZECOM's institutional capacity through the strengthening of its digital capabilities was identified. This paper outlines the framework for building the capabilities needed to successfully navigate the digital economy and align its operations toward such realization
\end{abstract}

Keywords: SOZECOM, Digital capability, Capacity Development, ICT

\section{INTRODUCTION}

The world as we know it is continually changing, and one of the fundamental reasons is digital transformation. The global economy is also undergoing digital transformation and it's happening at rapid speed. The digital economy refers to a broad range of economic activities that use digitized information and knowledge as key factors of production (World Economic Forum, 2016). The internet, cloud computing, big data, fintech, and other new digital technologies are used to collect, store, analyze, and share information digitally and transform social interactions. The digitization of the economy creates benefits and efficiencies as digital technologies drive innovation and fuel job opportunities and economic growth. The digital economy also permeates all aspects of society, influencing the way people interact and bringing about broad sociological changes (Global eSustainability Initiative and Accenture Strategy, 2015).
The digital economy is undermining conventional views about how organisations are structured; how organisations interact; and how people obtain services, information, and goods. Because digital products and services play an increasingly important role in the day-today operations of normal commerce, it no longer makes strategic sense to outsource these activities wholesale. Instead, many traditional establishments are starting to build internal digital capacity, which they can then enhance and extend with partnerships (La Trobe University, 2018). This ensures that these organisations have control over their long-term digital future. Organizations must rethink their structures and culture to better deal with new market environments and transaction models. The traditional organizations that prevailed before this shift will not work in the more global and fast-changing digital economy, where decision making is increasingly based on data rather than on the opinions.

Financial technologies have also introduced new ways of delivering financial services, particularly in facilitating 
payment and promoting financial inclusion in many developing countries. Fintechbased services further improved the efficiency of the payments system and digitized, networked, and intelligent information and communications technologies (ICTs) enable modern economic activities to be more flexible and responsive [4]. Digital transformation is about not only data and digital platforms but also how those advanced technologies can be utilized to maximize opportunities for innovative organizational models, processes, and services. While the world continues to benefit from this digital transformation, navigating the digital economy remains a challenge because of its complexity (World Economic Forum, 2016).

Given the widening digital skills gap and differences in the level of regulations and infrastructure, not all countries take full advantage of the benefits offered by the digital economy. Although the digital economy has the potential to radically change the social environment and economic activities of Africa. it has not yet fully realized the potential of harnessing digital technology for sustainable development, due to (among others) poor ICT infrastructure, inadequate skills development, and socioeconomic barriers that prevent much of the rural population from engaging in the digital economy (Bukht \& Heeks, 2017). The goal of financial services made available via digital means is to contribute to the reduction in poverty and deliver on the recognized benefits of financial inclusion in developing countries. Financial inclusion means the sustainable provision of affordable financial services that bring the poor into the formal economy. An inclusive system includes a range of financial services that provide opportunities for accessing and moving funds, growing capital, and reducing risk.

\section{Study Area}

The immediate area of Sozecom's operation is Sokoto State but because in most cases humanitarian need transcends geography, we also are increasingly engaged beyond Sokoto State and Nigeria. Sokoto State $\left(13^{\circ} 05^{\prime} \mathrm{N}, 05^{\circ} 15^{\prime} \mathrm{E}\right)$, located in Northwestern Nigeria has a population of about 5.7 million people predominantly $(80 \%)$ engaged in farming as primary occupation. The state covers a total of about $26,000 \mathrm{~km}^{2}$ and shares borders in the north with the Republic of Niger, to the east with Zamfara State and with Kebbi State to the southwest. It comprises 23 Local Government Areas and 86 districts.

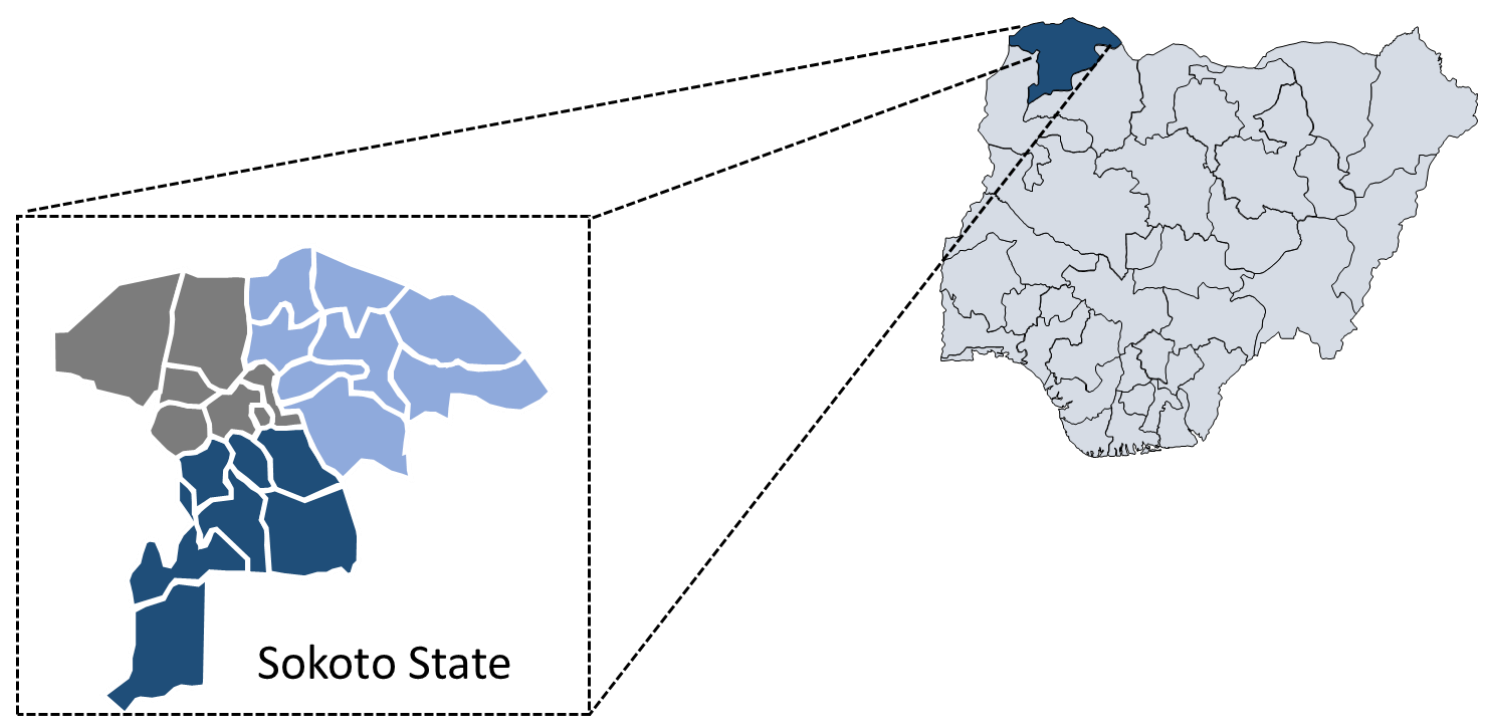

Figure 1. Location of Sokoto State 


\section{Contextual Setting}

In Sokoto state, North western Nigeria the majority of people living in rural areas are poor, financially excluded, digitally excluded subsistence farmers. Through the assistance of the Sokoto Sultanate Council, SOZECOM has extensive presence covering the entire 86 districts of the state, strategic collaboration with and access to other organizations also working in the same areas and a comprehensive agro-waqf initiative. Since nearly $50 \%$ of people in the rural areas already own or have access to a mobile phone, SOZECOM has seen the potential of greater financial inclusion, expansion of financial services to nonfinancial sectors, and the expansion of basic services to the poor particularly in the management of its extensive waqf system and state-wide zakat networks. An inclusive financial system is desirable and will provide opportunities for all people, particularly the poor, to access and move funds, grow capital, and reduce risk. With greater financial inclusion, individuals who were previously financially excluded will be able to invest in education, save and launch businesses, and this contributes to poverty reduction and economic growth.

To orchestrate this transition, SOZECOM has to as a first imperative, embark on institutional capacity development to create the requisite enabling environment. This requires not only the building of fresh capacity, but also the strengthening, mobilising and changing of existing capacity. Institutional capacity encompasses, on the one hand, the functions (tasks) that institutions should have, the competence (ability) to perform, and, on the other, the resources (human, technical and financial) and structures they need to that end. Capacity building is a cross-cutting issue, and it is critical for the achievement of all Sustainable Development Goals (SDGs). For this reason, capacity building is mainstreamed into the implementation of development programmes related to the SDGs across all sectors. The rapid pace of technological changes in the ICT sector demands a matching pace in the development of the skills and competencies required to fully leverage the benefits of these new technologies. The imperative for public services to fully exploit the potential of modern digital tools, technologies and approaches in order to improve delivery and save money has never been greater especially now when rising people's demand, needs and expectations coincides with a time of severe spending and resource constraints. Digital Capabilities are the key skills and capabilities a organization requires to transform itself into a sustainable and successful entity by considering digital technology as the enabling component. An institutional workforce that can make informed choices around the tools and technology they use, is essential in ensuring that institutions realise their strategic goals across all aspects of their operation (Roehrig \& Pring, 2016).

\section{DIGITAL CAPABILITY FRAMEWORK}

The SOZECOM Digital Capability Framework was developed in order to articulate the capabilities in a way that can be contextualized to suit the need of staff working in the different areas of SOZECOM operations such as zakat collection, zakat disbursement, zakat management, community and district waqf, property waqf, tree waqf, fund admnistration, investment, public awareness, planning and policy formulation among others. In developing the framework, SOZECOM has drawn upon the experience and expertise of professionals and staff working across higher education in a range of jobs in order to create a framework that can be adapted for all staff and integrated into staff development activities. Digital Capability Framework (DCF) is a digital transformation framework designed to help organizations innovate and coordinate 
digitally enabled transformation. It helps organizations analyse their current situation and identify new cases, which are enabled by technology trends in terms of six digital capabilities tailored to transform the organisation into a digital entity [8].

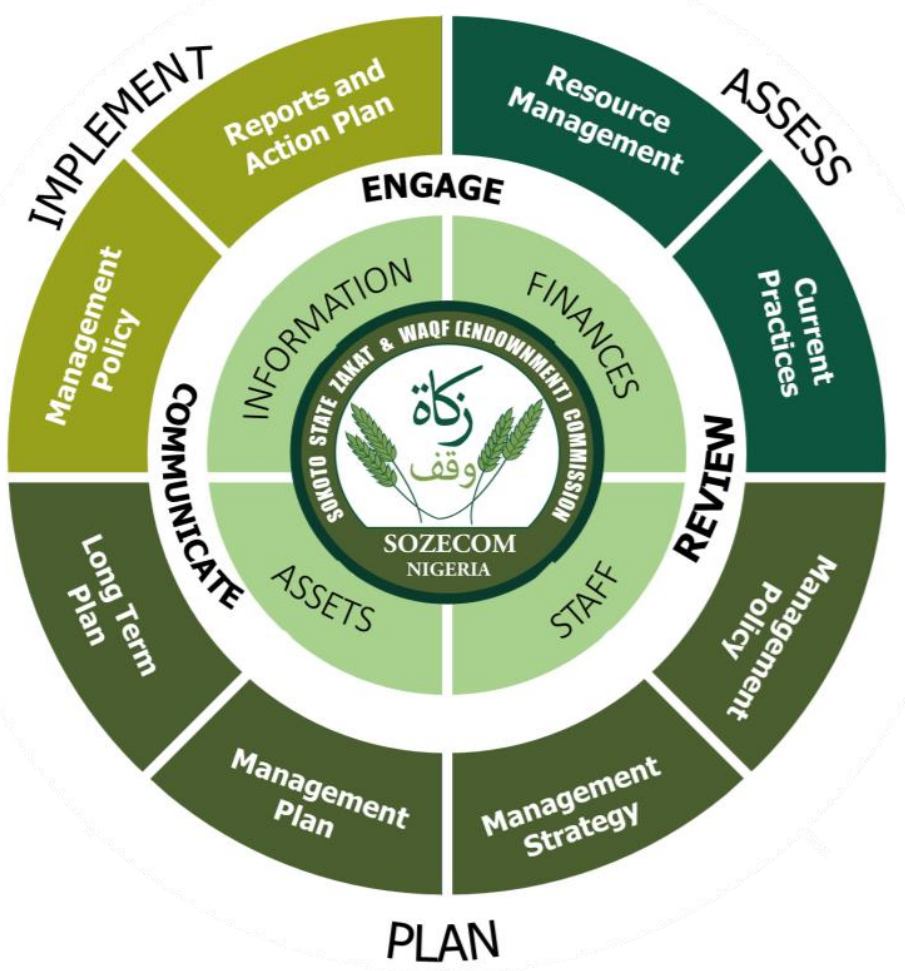

Figure 2. Sozecom Digital Capability Framework

Capacities can be enhanced through improved knowledge, personnel competencies and organisational processes, structures and systems. This will assist it in acquiring knowledge required to better design and implement systems, programs and services at the individual, organisational and institutional levels. It will also strengthen participatory mechanisms that would facilitate effective, responsive and accountable governance. There is the need to develop the capacity of SOZECOM in the broad areas of ICT proficiency, information and data literacy, media literacy, Networking and digital participation, digital research and innovation, E-learning and professional development, digital reputation and identity management. The unctional roles to be targetted include: leadership, administration, operations, IT facilities infrastructure, content/Knowledge mangement, research and scholarship, teaching and learning support,staff/educational development as well as public engagement/communication. To facilitate basic work readiness the aggregate competencies will ensure:

- Understanding, managing, customizing and efficiently using core ICT devices, apps, services and resources such as mobile devices, productivity software (e.g. wordprocessing, PowerPoint, e-mail, web browsing, Cloud tools).

- Finding, managing, sharing and organizing digital information in a range of media and ability to judge the quality, relevance, trustworthiness and value of information.

- Basic knowledge and management of digital safety, footprint, identity/reputation, security and compliance (e.g. data privacy and copyright). 
- Communicating effectively and with e- etiquette with different stakeholders, using a range of digital media, devices and tools e.g. e- mail, video conferencing, social media.

- Keeping up-to-date with collaboration, communication and information and management tools.

- Choosing and implementing appropriate collaboration, communication, information and management tools for use by teams.

- Following effective practices and

communication, collaboration, information management, productivity and self/team management.

- Influencing and motivating team members to use chosen digital tools and guiding them to appropriate awareness- raising, training and support.

- Managing risks with teams when using digital tools e.g. privacy, identity/reputation, data protection, security. key principles for efficient digital

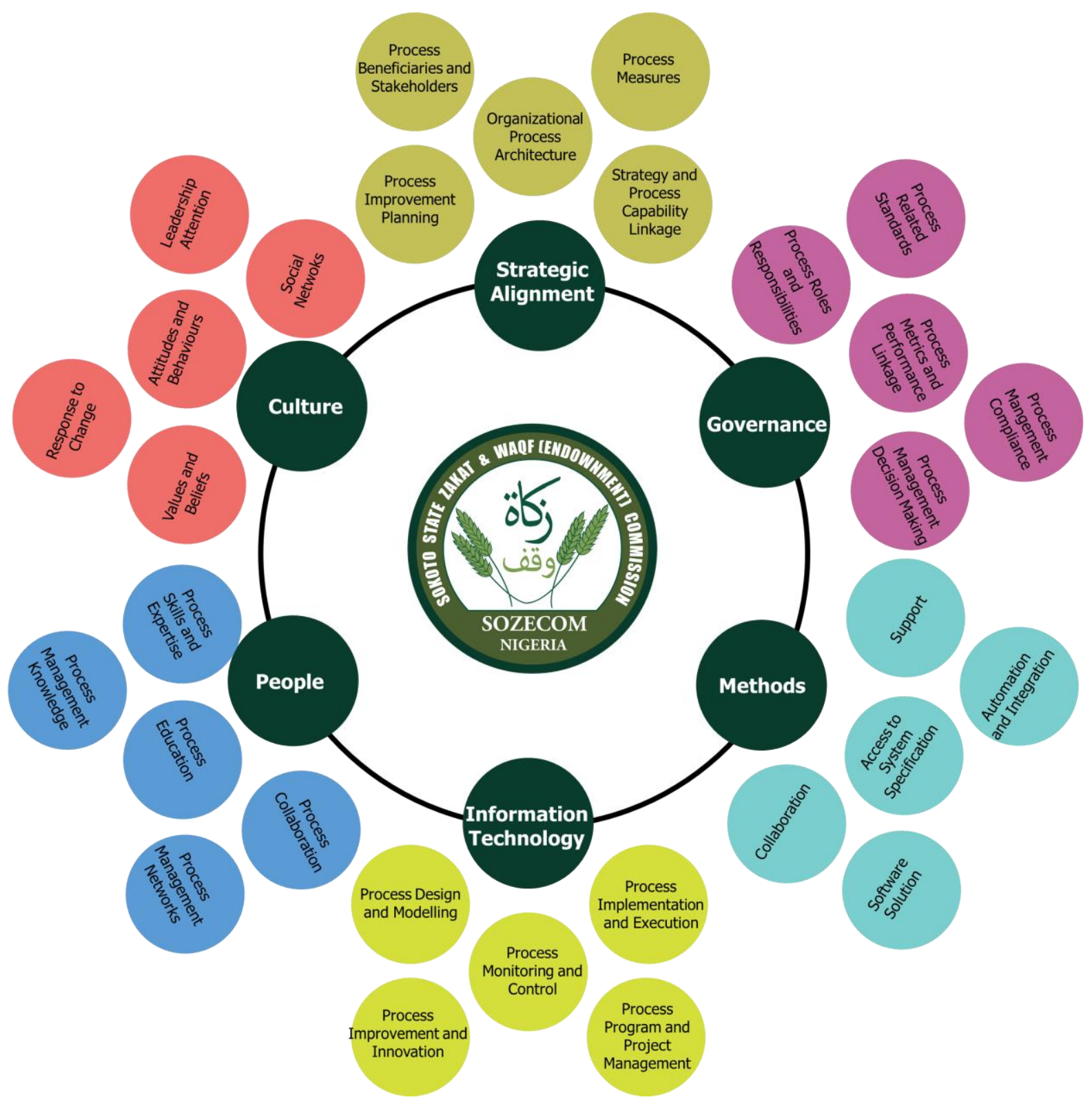

Figure 3. Overview of Sozecom envisione transformation 


\section{Challenges and Constraints}

Capacity building usually a slow process so the pace of this transformation is slowed by paucity of fund, existing workload and other responsibilities. Another constraint is the limited IT infrastructure and services.
For this reasons and to overcome these limitations, a gradual and phased transformation is chosen. The imperative of overcoming these limitations is recognized and the efficiency gains are expected to overweigh the challenges.

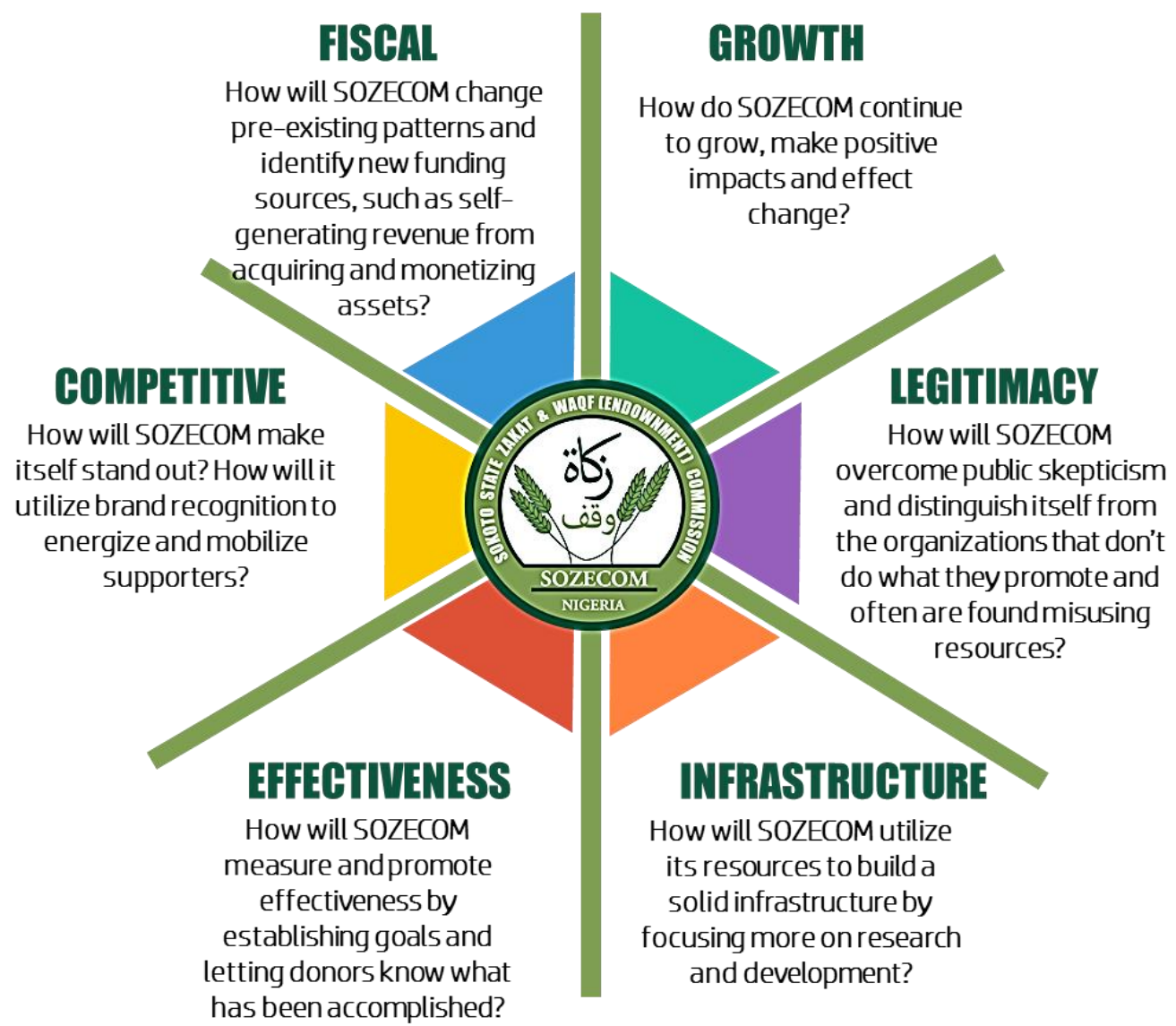

Figure 4. General Challenges facing Sozecom

\section{CONCLUSION}

A succesfully reformed Sozecom will improve the outlook for the general administration of zakat and waqf in Sokoto state. A digitally empowered Sozecom will deliver on the promise of greater financial inclusion, expansion of financial services to rural areas of the state, and the expansion of basic services to individuals this in turn will help in accomplishing the aim of eliminating poverty in the state.

\section{REFERENCE}

World Economic Forum. (2016). Understanding The Impact of Digitalization on Society. Retrieved from http://reports.weforum.org/

Global e-Sustainability Initiative \& Accenture Strategy. (2015). \#SMARTer 2030: ICT Solutions for 21st Century Challenges. Brussels, Belgium: GeSI.

La Trobe University. (2018). Skills for a Digital World: Digital Literacies Framework Enabling a Digital 
Future. Australia: La Trobe University.

Bukht, R., \& Heeks, R. (2017). Defining, Conceptualizing and Measuring the Digital Economy. Development Informatics Working Paper, (68).

Roehrig, P., \& Pring, B. (2016). The Work Ahead: Mastering the Digital Economy. Teaneck, NJ: Cognizant.
Muhammad Lawal Maidoki Sokoto State Zakat and Waqf (Endowment) Commission Sokoto, Nigeria Sozecom.Zakat@gmail.com 